\title{
PERFORMANCE OF A STATIONARY SAVONIUS ROTOR WITH CIRCULAR ARC BLADE PROFILE
}

\author{
Anik Adhikary, Md. Quamrul Islam* and Mohammad Ali \\ Department of Mechanical Engineering \\ Bangladesh University of Engineering \& Technology (BUET), Dhaka-1000, Bangladesh \\ *Corresponding e-mail: quamrul@me.buet.ac.bd
}

\begin{abstract}
Static torque and drag coefficients of a stationary Savonius rotor with circular arc blade profile have been investigated by measuring the pressure distribution on the blade surfaces for different rotor angles. Experiments have been performed at a Reynolds Number $1.8 \times 10^{5}$ with rotors having no overlap. Results indicate that static torque coefficients vary considerably with the rotor angle.
\end{abstract}

Keywords: Savonius rotor, blade profile, drag coefficient.

\section{INTRODUCTION}

The Savonius rotor has been subject of interest since the 1930's and has been studied extensively. It is a vertical axis wind turbine and has a lower efficiency as compared to other vertical axis wind turbines such as Darrieus Rotor. Nevertheless, it is used as an alternative to wind power extraction because of its simple design and good starting torque at low wind speeds ${ }^{1,5,10,13}$. Rigorous studies on the performance characteristics of the Savonius rotor are found in the literatures and these enable the identification of an optimum geometrical configuration for practical design $n^{2,4,6,9,11}$. However, only a few studies are reported in the literatures which give information regarding the total aerodynamic load on the structure and mechanism of the rotation of the rotor. This paper attempts an experimental study on the aerodynamic load on a stationary Savonius rotor with different multiple number of blades.

\section{EXPERIMENTAL SETUP AND PROCEDURE}

The objectives of the investigation of wind loading on the circular arc bladed Savonius rotor have been realized essentially with the help of a subsonic wind tunnel experimental set up of the Savonius rotor and an inclined manometer bank. The schematic diagram of the wind tunnel is shown in Figure 1.

\section{The wind tunnel}

The open circuit subsonic wind tunnel was $6.55 \mathrm{~m}$ $(21.5 \mathrm{ft})$ long with a test section of $(49 \mathrm{~cm} \times 49 \mathrm{~cm})$ cross-section. Figure 1 depicts the wind tunnel used for the experiment. The successive sections of the wind tunnel comprised of converging mouth entry, perspex section, rectangular section, fan section (two rotary axial flow fans), butterfly section, silencer with honeycomb section, an eddy breaker, diverging section, converging section, $2 \mathrm{ft}$ long rectangular section, $1 \mathrm{ft}$ long flow straightened section, $2 \mathrm{ft}$ long rectangular exit section. The central longitudinal axis of the wind tunnel was maintained at a constant height from the floor.

\section{The rotor}

The Savonius rotor was made up of three blades of diameter, $\mathrm{d}=72.75 \mathrm{~mm}$ and height, $\mathrm{H}=300 \mathrm{~mm}$. The blades were made of PVC material. The whole rotor was fixed on an iron frame by using two side shafts and two ball bearings. The pressure measurements were done at 12 pressure tappings on each blade. The tappings were made with copper tubes of $1.5 \mathrm{~mm}$ outer diameter and $10 \mathrm{~mm}$ length which were press fitted to the tapping holes. The tappings were located at the mid-plane of one side of each blade, so that pressure distribution at every $10^{\circ}$ on the blade surface could be measured. The pressure tappings were connected to an inclined multi-manometer (manometric fluid was water and hadan accuracy of $\pm 0.1 \mathrm{~mm}$ of water column) through $2 \mathrm{~mm}$ PVC tubes. The pressures were measured at every $10^{\circ}$ interval of rotor angle (Figure 3.5 ), so that a detailed picture of the aerodynamic loading and torque characteristics could be obtained.

\section{AERODYNAMIC CHARACTERISTICS CALCULATION}

The flow pattern produced by the rotor blades is characterized by complicated floe phenomenon such as high turbulence, unsteadiness and flow separation $1,6,11,14$. The combined effect of these floe features in turn produces pressure differences between the front and back surfaces of the blades. These pressure differences result in the calculation of the aerodynamic forces from numerical integrations. Pressure coefficient is defined as

$$
C_{p}=\frac{P-P_{0}}{\frac{1}{2} \rho U_{0}^{2}}
$$

where, $\mathrm{P}-\mathrm{P}_{0}=$ Difference between blade and atmospheric pressure in Pascal, 
$\rho=$ Density of air $=1.2 \mathrm{~kg} / \mathrm{m}^{3}$,

$\mathrm{U}_{0}=$ Free stream velocity $=13 \mathrm{~m} / \mathrm{s}$.

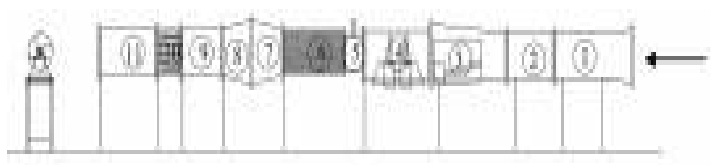

Figure 1. The Wind tunnel

For Savonius rotor, at a particular rotor angle, $\alpha$ the rotor blades experience forces (per unit span length) due to pressure difference between the concave surface and convex surface and these forces can be resolved into two components, $F_{n}$ and $F_{t}$. Since the blade surfaces are circular, $F_{n}$ and $F_{t}$, pass through the center of the circle. The drag coefficients in normal and tangential directions can be written as follows

$$
\begin{aligned}
& C_{\mathrm{n}}=\frac{\mathrm{F}_{\mathrm{n}}}{\frac{1}{2} \rho \mathrm{U}_{0}^{2} \mathrm{~d}} \\
& \mathrm{C}_{\mathrm{t}}=\frac{\mathrm{F}_{\mathrm{t}}}{\frac{1}{2} \rho \mathrm{U}_{0}^{2} \mathrm{~d}}
\end{aligned}
$$

To obtain the drag coefficients in the normal and tangential directions of the chord, the values of $F_{n}$ and $F_{t}$ must be known beforehand. The values of the forces $F_{n}$ and $F_{t}$ are obtained by integrating the pressure for a blade as follows

$$
\mathrm{F}_{\mathrm{n}}=\int_{0}^{\pi} \Delta \mathrm{p} \frac{\mathrm{d}}{2} \cos \phi \mathrm{d} \phi=\sum_{\mathrm{i}=1}^{12} \Delta \mathrm{p}_{\mathrm{i}} \frac{\mathrm{d}}{2} \cos \phi_{\mathrm{i}} \Delta \phi_{\mathrm{i}}
$$

and similarly,

$$
\mathrm{F}_{\mathrm{t}}=\sum_{\mathrm{i}=1}^{12} \Delta \mathrm{p}_{\mathrm{i}} \frac{\mathrm{d}}{2} \sin \phi_{\mathrm{i}} \Delta \phi_{\mathrm{i}}
$$

where, $\Delta \mathrm{p}_{\mathrm{i}}$ is the difference in pressure on the concave and convex surfaces at a particular pressure tapping, i. This $\Delta \mathrm{p}_{\mathrm{i}}$ is multiplied by the differential area $\frac{\mathrm{d}}{2} .1 . \mathrm{d} \phi$ considering unit height of the blade to obtain the value of differential tangential and normal forces. Then numerical integration is carried out for the whole diameter of each blade corresponding to the limit 0 to $\pi$ for obtaining the value of $F_{n}$ and $F_{t}$. The force $F_{n}$ is responsible for producing a torque on the shaft of the rotor and this torque coefficient for a single blade at a particular rotor angle can be written as

$$
\mathrm{C}_{\mathrm{q}}(\alpha)=\mathrm{C}_{\mathrm{n}}(\alpha) \times \frac{1-\mathrm{s}}{2-\mathrm{s}}
$$

The total static torque coefficient produced on the rotor shaft by the three blades can be expressed as follows

$$
\begin{aligned}
\mathrm{C}_{\mathrm{Q}}(\alpha) & =\left[\mathrm{C}_{\mathrm{n}}(\alpha)+\mathrm{C}_{\mathrm{n}}\left(\alpha+120^{0}\right)+\mathrm{C}_{\mathrm{n}}\left(\alpha+240^{0}\right)\right] \\
& \times \frac{1-\mathrm{s}}{(2-\mathrm{s})^{2}}
\end{aligned}
$$

where,

$\mathrm{C}_{\mathrm{n}}(\alpha), \mathrm{C}_{\mathrm{n}}\left(\alpha+120^{\circ}\right)$ and $\mathrm{C}_{\mathrm{n}}\left(\alpha+240^{\circ}\right)$ refer to the drag coefficients of the first, second and third blades respectively at rotor angle $\alpha$.

\section{RESULTS AND DISCUSSIONS}

Normal drag coefficient, $\mathrm{C}_{\mathrm{n}}$ for an individual blade is shown in Fig. 2 for different rotor angles. For the first blade, normal drag coefficient $C_{n}(\alpha)$ increases with the increase of rotor angle from $\alpha=0^{\circ}$ to $40^{\circ}$, and then drag coefficient decreases with the increase of the rotor angle $\alpha$, up to $90^{\circ}$. The drag coefficient $C_{n}(\alpha)$ for the first blade which is responsible for the torque production is positive for a rotor angle of $0^{\circ}$ to $80^{\circ}$ and reaches its maximum value at $\alpha=40^{\circ}$. At $\alpha=90^{\circ}$ the value becomes negative. The drag coefficient $\mathrm{C}_{\mathrm{n}}\left(\alpha+120^{\circ}\right)$, for the second blade, is higher compared to that of the first blade. Drag coefficient $\mathrm{C}_{\mathrm{n}}\left(\alpha+120^{\circ}\right)$, for the second blade is always positive, i.e. is in favor of torque production from $\alpha=0^{0}$ to $110^{\circ}$. The drag coefficient $C_{n}\left(\alpha+240^{\circ}\right)$, decreases in the negative values with the increase of rotor angle.

Tangential drag coefficient, $C_{t}$ with individual blade effect is shown in Fig. 3 for different rotor angles. For the first blade, tangential drag coefficient, $\mathrm{C}_{\mathrm{t}}(\alpha)$ increases with the increase of rotor angle from $\alpha=0^{0}$ to $40^{\circ}$ and then decreases up to $90^{\circ}$. The drag coefficient, $\mathrm{C}_{\mathrm{t}}(\alpha)$ for the first blade which is responsible for thrust production on the support of the rotor, is positive for the rotor angle of $0^{\circ}$ to $90^{\circ}$ and reaches its maximum value at $\alpha=40^{\circ}$. At $\alpha=90^{\circ}$ becomes slightly negative. The drag coefficient $\mathrm{C}_{\mathrm{t}}\left(\alpha+120^{\circ}\right)$, for the second blade, is higher compared to that of the first blade. Drag coefficient $\mathrm{C}_{\mathrm{t}}\left(\alpha+120^{0}\right)$ for the second blade is positive, i.e. it is in favor of thrust production from $0^{0}$ to $110^{\circ}$ angle of rotation. The drag coefficient $\mathrm{C}_{t}\left(\alpha+240^{0}\right)$, for the third blade, 
decreases in the negative value from $\alpha=240^{\circ}$ to $\alpha=360^{\circ}$ with the increase of rotor angle. So, it produces negative thrust from $\alpha=240^{\circ}$ to $\alpha=360^{\circ}$.

Total static torque coefficient at different rotor angles is shown in Fig. 4. The nature of this curve is exactly similar to the normal drag coefficient, $C_{n}$ with combined effect of three blades. Only difference is that the value of torque coefficient is greater than normal drag coefficient with combined blade effect. Here, the total static torque increases with the increase of the rotor angle up to $30^{\circ}$ and reaches its maximum value and then decreases to a negative value at $\alpha=90^{\circ}$. The curve repeats from $120^{\circ}$ to $230^{\circ}$ and again from $240^{\circ}$ to $350^{\circ}$ angle of rotation.

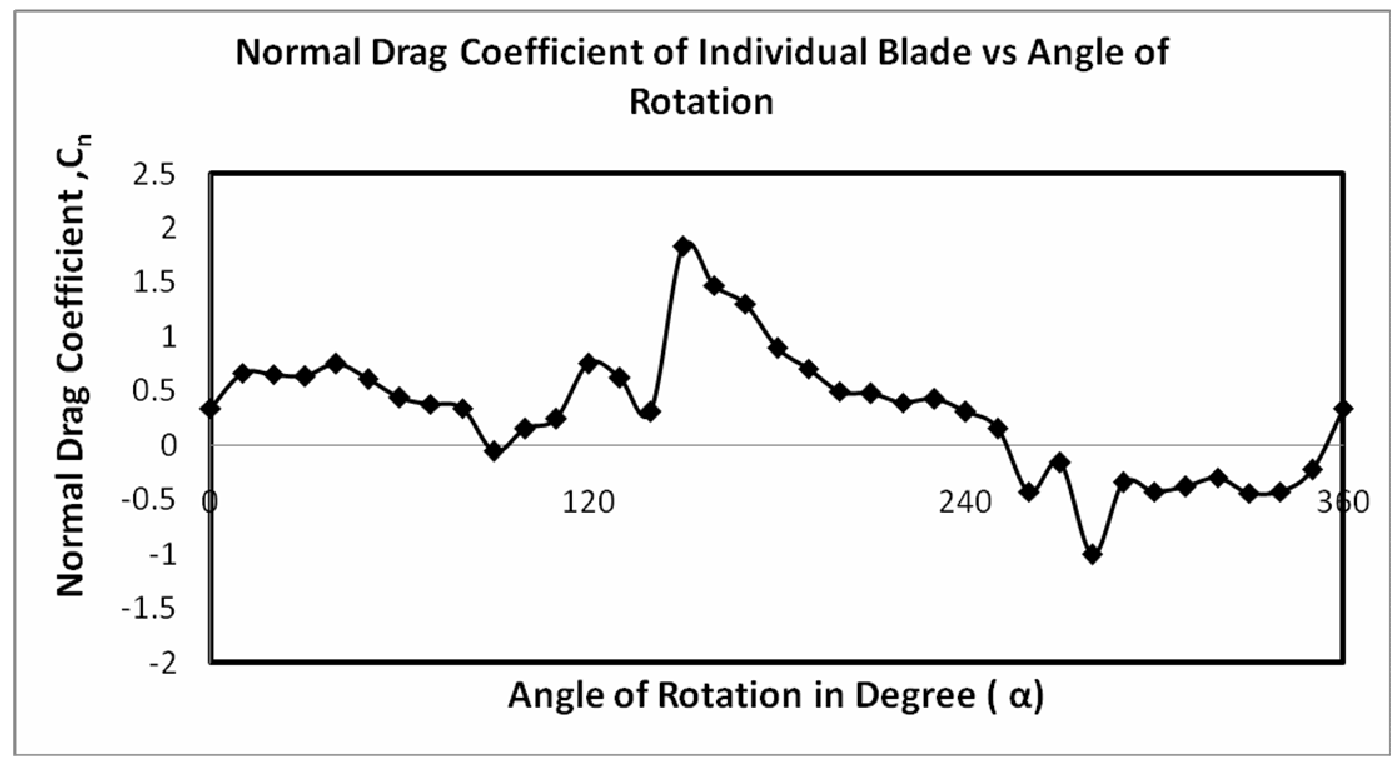

Figure 2. Normal drag coefficient of individual blade effect

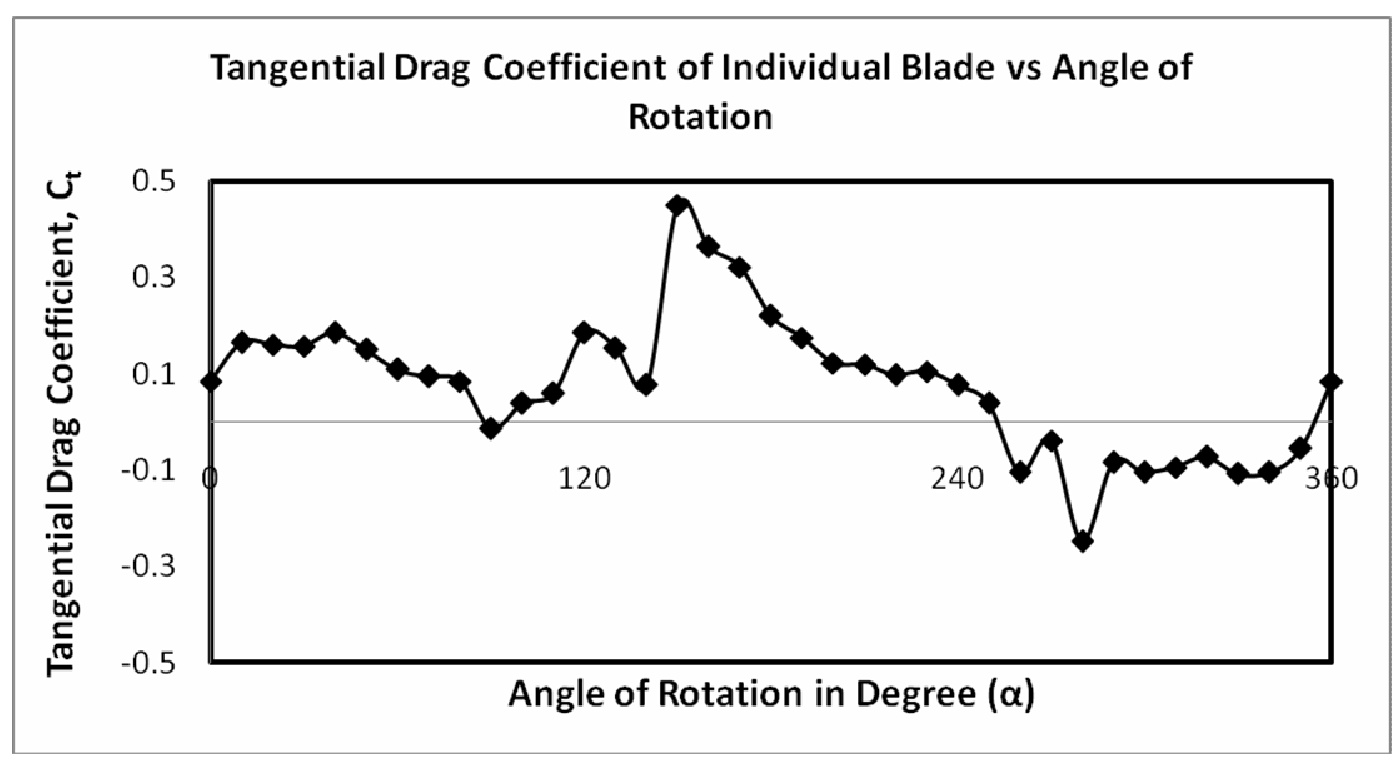

Figure 3. Tangential drag coefficient of individual blade effect 


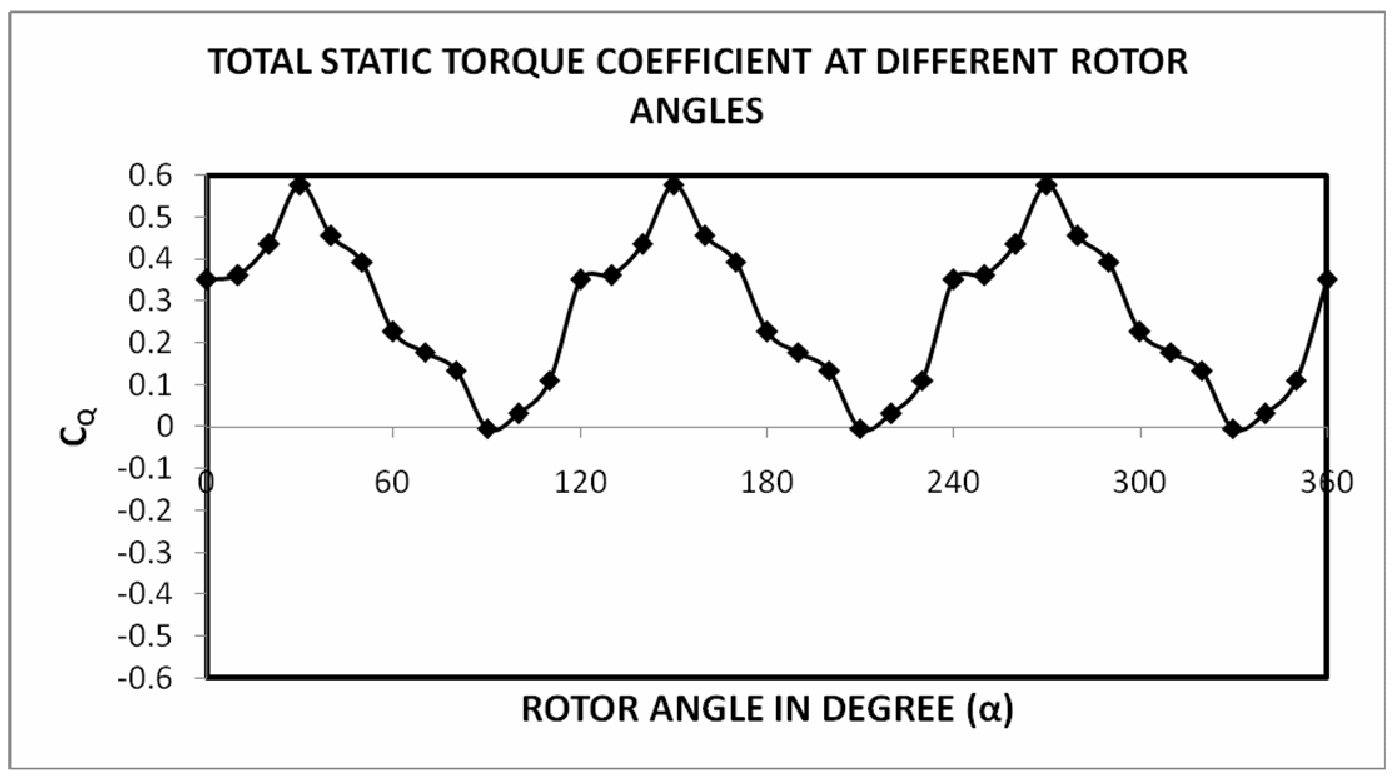

Figure 4. Total static torque coefficient at different rotor angles

\section{NOMENCLATURE}

\begin{tabular}{|c|c|c|c|}
\hline a & Overlap distance & $\mathrm{P}$ & Pressure on blade \\
\hline $\mathrm{C}_{\mathrm{p}}$ & Pressure coefficient & $\Delta \mathrm{p}$ & $\begin{array}{l}\text { Difference of pressure between concave and } \\
\text { convex surfaces of a blade }\end{array}$ \\
\hline $\mathrm{C}_{\mathrm{pb}}$ & $\begin{array}{l}\text { Pressure coefficient for concave surface } \\
\text { of the blade }\end{array}$ & $\mathrm{P}_{\mathrm{a}}$ & Atmospheric pressure \\
\hline $\mathrm{C}_{\mathrm{px}}$ & $\begin{array}{l}\text { Pressure coefficient for convex surface of } \\
\text { the blade }\end{array}$ & $\mathrm{Re}$ & Reynolds number \\
\hline $\mathrm{C}_{\mathrm{t}}$ & $\begin{array}{l}\text { Drag coefficient in the transverse } \\
\text { direction of the chord }\end{array}$ & $\mathrm{S}$ & Ratio of overlap distance to diameter of blade \\
\hline $\mathrm{C}_{\mathrm{n}}$ & $\begin{array}{l}\text { Drag coefficient in the normal direction } \\
\text { of the chord }\end{array}$ & $\mathrm{T}$ & Static torque on a blade \\
\hline $\mathrm{C}_{\mathrm{q}}$ & Static torque coefficient for a single blade & $\mathrm{U}_{0}$ & Free stream velocity \\
\hline $\mathrm{C}_{\mathrm{Q}}$ & Total static torque coefficient & $\mathrm{V}_{\mathrm{r}}$ & Relative velocity \\
\hline $\mathrm{d}$ & Diameter of blade & $\mathrm{V}_{\mathrm{w}}$ & Component of relative velocity along $\mathrm{U}_{0}$ \\
\hline $\mathrm{D}$ & Diameter of the rotor & $\alpha$ & Rotor angle \\
\hline $\mathrm{F}_{\mathrm{n}}$ & Normal forces acting on a blade & $\phi$ & Angle of pressure tappings \\
\hline $\mathrm{F}_{\mathrm{t}}$ & Tangential forces acting on a blade & $\lambda$ & Tip speed ratio, $\mathrm{D} \omega / 2 \mathrm{U}_{0}$ \\
\hline $\mathrm{H}$ & Height of the rotor & $\omega$ & Angular speed of the rotor \\
\hline$\Delta \mathrm{h}_{\mathrm{w}}$ & Specific weight of manometer liquid & $v$ & Kinematic viscosity of air \\
\hline
\end{tabular}




\section{CONCLUSION}

The total static torque coefficients for the rotor at different rotor angles are analyzed. From the results obtained the following conclusions can be drawn for a stationary savonious rotor with circular arc blade profile.

i. The normal drag coefficient for individual blade increases gradually from $0^{\circ}$ and it becomes the maximum at around $150^{\circ}$ angle of rotation. After $240^{\circ}$ angle of rotation it becomes negative up to $350^{\circ}$.

ii. However, tangential drag coefficient for individual blade becomes the maximum at around $130^{\circ}$ angle of rotation and up to $240^{\circ}$ its value remains positive. Again, after $260^{\circ}$ angle of rotation the value becomes negative.

iii. The total torque coefficient becomes the maximum at $30^{\circ}, 150^{\circ}$ and $260^{\circ}$ positions and the variation is more or less cyclic which is evident from the experimental values.

\section{REFERENCES}

1. Lysen, E, H., Bos, H. G. and Cordes, E. H. , 1978, "Savonius Rotors for Water Pumping”, SWD Publication, Amersfoort, The Netherlands.

2. Beurskens, H. J. M., 1980, "Low Speed Water Pumping Wind Mills: Rotor Tests and Overall Performance", Proe. of $3^{\text {rd }}$ Int. Symp. On Wind Energy Systems, Copenhagen, Denmark.

3. Park, J., 1975, "Simplified Wind Power System for Experimentry”, Helion Inc., California, USA.

4. Sivasegaram, S., 1977, "Design Parameters Affecting the Performance of Resistance Type Rotors", Wind Engineering, vol. 1, pp. 207-217.

5. Newman, B. G., 1974, "Measurements on a Savonius Rotor with a Variable Gap", Proc. Symposium on Wind Energy: Achievements and Potential, Sherbrooke, Canada.
6. Lysen, E, H., 1983, "Introduction to Wind Energy", Steering Committee of Wind Energy for Developing Countries, P.O. Box 85, Amersfoort, The Netherlands.

7. Wilson, R. E. and Walker, S. N., 1981, "Performance Analysis Program for Propeller Type Wind Turbines", Oregon State University, March, USA.

8. Ogawa, T. and Yoshida H., 1986, "The Effects of a Deflecting Plate and Rotor and Plates", Bull. JSME, vol. 29, pp. 2115-2121.

9. Islam, A. K. M. S., Islam, M. Q., Razzaque, M. M. and Ashraf, R., 1995, "Static Torque and Drag Characteristics of an S-Shaped Savonius Rotor and Prediction of Dynamic Characteristics", Wind Engineering, vol. 19, no. 6.

10. Huda, M. D., Selim, M. A., Islam A. K. M. S. and Islam M.Q., 1992, "The performance of an SShaped Savonius Rotor with a Deflecting Plate", RERIC Int. Energy J., vol. 14, no. 1, pp. 25-32.

11. Gavalda, J., Massons, J. and Diaz F., 1991, "Drag and Lift Coefficients of the Savonius Wind Machine", Wind Engineering, vol. 15, pp. 240-246. 12. Islam, A. K. M. S., Islam M. Q., Mandal A. C. and Razzaque, M. M., 1993, "Aerodynamic Characteristics of a Stationary Savonius Rotor", RERIC Int. Energy J., vol. 15, no. 2, pp. 125-135. 13. Bowden, G. J. and McAleese, S. A., 1984, "The Properties of Isolated and Coupled Savonius Rotors", Wind Engineering, vol. 8, no. 4, pp. 271288. 